\title{
Epilepsy, Neuropsychological Deficits, and EEG Lateralization
}

\author{
Patrick C. Fowler and Herbert C. Richards \\ University of Virginia \\ Stanley Berent \\ University of Michigan
}

Thomas J. Boll

University of Alabama (Birmingham)

\begin{abstract}
One hundred eight epileptic patients 159 men, 49 women; $55 \%$ partial seizures, $45 \%$ generalized) were examined on 45 indices comprising a modified Halstead Neuropsychological Test Battery. Factor analyses identified five dimensions: Ver. bal Comprehension, Perceptual Organization, Selective Attention, Motor Skills, Abstract Reasoning. These factors are similar to those previously reported for neurocognitive abilities in several different populations. Relative deficits on Ver. bal Comprehension and Abstract Reasoning were related, as predicted, to left hemispheric dysfunction as indexed by EEG localization. Perceptual Organiza tion demonstrated a further, predictable relationship to right hemispheric funttion. Deficits on Selective Attention were not clearly lateralized, being corretated with a wide variety of electroencepholographic abnormalities. The implications of these findings for the use of neurocognitive profiles in treatment planning for this population are discussed.
\end{abstract}

Portions of these findings were previously reported at the 1985 Annual European Meeting of the International Neuropsychological Society in Copenhagen, Denmark.

Support for this research was partially funded by the National Institute of Neurological and Communicative Disorders and Stroke, contract numbers: N01-NS-5-2329 (Biopsychosocial Aspects of Epilepsy, Dr. Boll) and N01-NS-7.2373 (Perceptual Studies in Epilepsy, Dr. Berent).

Statistical analysis was supported by a grant to the senior author from the Academic Computing Center, University of Virginia.

Requests for reprints should be sent to Patrick C. Fowler, PhD, Division of Child \& Family Psychiatry, University of Virginia Medical Center, Box BRH (Stafford Hall), Charlottesville, VA 22908. 
Studies of epilepsy have documented the unpredictable, yet potentially devastating, effects of these disorders on the higher cortical functions of children and adults. (Brown \& Reynolds, 1981; and Dodrill, 1981, provide excellent overviews of the many complex issues involved.) Nonetheless, the specific associations between seizure type (e.g., focal vs. generalized) and the resulting dysfunction are unclear and quite confusing. Methodological issues involving the use of different nosologies for classifying seizures, dissimilarities among patient populations, diagnostic errors, and highly variable individual differences among epileptics (e.g., variations in age, age-atonset of seizure disorders, seizure frequency, seizure duration, exposure to pharamocological therapy) have all been long recognized as contributing to the lack of clarity in this area (Brown \& Reynolds, 1981; Hermann \& Whitmann, 1984; Pincus \& Tucker, 1985; Stores, 1981).

Although there is evidence (and some agreement) that generalized seizures have the most predictable effects on neurocognitive abilities (Dodrill, 1986; Dodrill \& Wilkus, 1978; Loiseau et al., 1983), it has been more difficult to establish the specificity of the effects of focal seizures on neuropsychological variables (Camfield et al., 1984; Ladavas, Umilta, \& Provinciali, 1979). It remains, for example, unresolved whether the primary effect of any type of seizure disorder is to simply introduce cumulative and nonspecific deficits on neurocognitive abilities.

Previous researchers in this field have not, however, consistently analyzed their data by identifying higher-order dimensions of individual differences. Instead, where batteries of neuropsychological measures have been explicitly constructed to probe the effects of epilepsy (e.g., Dodrill, 1981), the examination of the results has proceeded almost exclusively on a variable-byvariable basis. This research orientation in clinical studies of epilepsy stands in contrast to the widespread use of well-designed multivariate investigations of neurocognitive processes in normal or other non-neurologically impaired populations (Carroll \& Maxwell, 1979).

Whenever investigators have examined the configuration of entire sets of variables (e.g., Newby, Hallenbeck, \& Embretson, 1983; Royce, Yeudall, \& Bock, 1976), structurally simple schemes of verbal-cognitive, spatial-perceptual, memory, and sensorimotor factors have emerged. Such findings have paralleled the distinctions made by Lezak (1983) between verbal, nonverbal, and mental activity variables (e.g., selective attention).

One assessment approach in clinical neuropsychology that does lend itself to addressing such issues is the major tradition initiated by Halstead (1947) and then pursued by Reitan (1966; Reitan \& Davidson, 1974) and his colleagues (Boll, 1978; Russell, Neuringer, \& Goldstein, 1970). The Halstead procedures have been progressively refined over the past four decades and provide a suitable set of variables for multivariate investigations. But only recently have some investigators (e.g., Newby et al., 1983; Swiercinsky, 
$1978,1979)$ begun to systematically explore the structure of the Halstead's indices.

The present study was undertaken to address these issues by first conducting a factor analysis of adult epileptics' behavior on a modified Halstead Battery, and then relating the factors that emerged to a lateralization index derived from electroencephalographic data. Our intent was to examine the association of the Halstead's dimensions to localized neurological abnormalities (i.e., ictal foci). According to conventional wisdom, some higher cortical functions, such as verbal comprehension and abstract reasoning, are more dependent on the functional integrity of the left cerebral hemisphere, while others, such as spatial-perceptual organization, are more dependent on the right. It follows, then, that verbal-cognitive abilities may be most impaired among epileptics whose seizure foci are located in the left hemisphere; spatial-perceptual organization should be most impaired among those whose seizure foci are located in the right. Differential predictions for mental activity variables (e.g., selective attention) are not possible, since disruptions in these higher cortical functions can be equally provoked by focal as well as more widespread involvement of the cerebral hemispheres (Neisser, 1976; Pincus \& Tucker, 1985). More specifically, we are predicting that when general level of functioning is controlled, epileptic patients whose electroencephalograms suggest left hemispheric neuroelectric abnormalities (viz., left-sided ictal foci) will score lower on verbal comprehension and abstract reasoning. Those whose EEG's suggest right hemisphere abnormalities (viz., right-sided foci) will score lower on perceptual organization.

\section{METHOD}

\section{Subjects and Procedures}

One hundred eight epileptic adults ( 59 men and 49 women), who were referred for neuropsychological evaluation to the Comprehensive Epilepsy Program at the University of Virginia Medical Center, participated in this study. As a part of a wider assessment, a modified Halstead Battery of 45 neuropsychological measures was administered. In all, $54.5 \%$ of the sample were classified as "partial seizure disorder," while $45.5 \%$ were classified as "generalized seizure disorder." Etiologies were quite varied, encompassing head injury, infectious disease (e.g., encephalitis), intracranial tumors, and cerebrovascular disease (e.g., stroke). In over half of this sample, no firm etiology could be determined, a finding which is compatible with known statistics on the epilepsies (Epilepsy Foundation of America, 1975), especially in the instance of late onset. At the time of their neuropsychologcal evaluations, $91.2 \%$ of the sample were receiving at least one anticonvulsant (usually Phenobarbital or Dilantin) and, in many instances $(63.1 \%$ and 
$24.1 \%$, respectively), two and three anticonvulsants. (These characteristics are comparable to those reported by Fowler, Richards, \& Boll, 1980, where further information about this sampie can be found.) Informed consent, as required (and approved) by the University of Virginia Hospital, was obtained for all patients priori to evaluation.

\section{Factor Analysis}

The $\mathbf{4 5}$ measures of the modified Halstead Battery were intercorrelated. A Kaiser-Meyer-Olkin estimate of the variables' sampling adequacy, a Bartlett's test of sphericity, and the number of off-diagonal elements greater than .09 in the anti-image covariance matrix were computed to determine the suitability of the correlation matrix for factor analysis (Dzuiban \& Shirkey, 1974). In addition, a Scree Test (Cattell, 1966) was conducted to initially estimate an appropriate number of factors for subsequent analyses. The results of this test suggested to us that four, five, or six factors might provide reasonable spaces for interpreting the intercorrelations among the measures. Accordingly, three maximum likelihood factor analyses were computed using program JFACTOR from SPSS (Nie, Hull, Jenkins, Steinbrenner, \& Bent, 1979). After computing the initial orthogonal factor matrices, each solution was rotated to simple structure according to the direct oblimin criterion. The clearest simple structure was evident in five-factor space, and this model was selected as the basis for subsequent interpretation and analysis. Factor scores for each of these five dimensions were then computed, and a priori contrasts made on the basis of the hypotheses guiding the investigation.

\section{Lateralization Analysis}

Finally, EEG laterality indices were available for 87 of the original 108 patients. These patients' EEG's were interpreted by board-certified neurologists or EEG Fellows who were responsible for classifying these individuals into four categories: right-sided foci only $(N=29)$, left-sided foci only $(N=13)$, bilateral foci $(N=10)$, and generalized $(N=35)$. The marked nonorthogonality of the design for these analyses (especially, the smaller numbers of subjects with left-sided or bilateral foci) limits, or at least conditions, the extent to which the findings can be easily generalized. Several of the original patients either did not have current EEG's available at the time of their neuropsychological assessment or the records did not lend themselves to easy classification. These subjects were, consequently, eliminated from subsequent analyses. 


\section{RESULTS AND DISCUSSION}

\section{Factor Analysis}

Means and standard deviations for all the variables are shown in Table 1. Characteristics of the correlation matrix bearing upon its suitability for factor analysis are presented in Table 2 . It can be seen that these statistics are satisfactory, (Dzuiban \& Shirkey, 1974) and that it is reasonable to factor analyze this correlation matrix. The rotated loadings for the five-factor solution are displayed in Table 3.

The factors were interpreted in the following manner: Verbal Comprehension (Factor I), a dimension dominated by high loadings of the WAIS's "Verbal Comprehension" grouping as well as high loadings for achievement indices; Motor Skills (Factor II), a group of tasks involving indices related primarily to motor strength and speed; Perceptual Organization (Factor III) is characterized by high loadings for haptic-motor performance as well as subtests from the WAIS's Performance Scale that contribute to its "Perceptual Organization" factor; Selective Attention (Factor IV), a grouping of tasks that includes the WAIS's "Freedom-from Distractibility" triad (viz., Arithmetic, Digit Span, and Digit Symbol) as well as a variety of other tasks from the Halstead Battery and its ancillary procedures that index attention, concentration, and the ability to maintain a mental set; Abstract Reasoning (Factor V), a quartet from the Category Test of the Halstead Battery, reflecting concept formation ability as well as the integrity of short-term memory functions. These factors are analogous to dimensions that have been reported by earlier investigators (c.g., Royce et al., 1976): They reflect broadly based dimensions of mental ability that are known to be relevant to performance on neuropsychological evaluation procedures.

The intercorrelations among the obliquely rotated factors are also shown in Table 3. It can be seen that Verbal Comprehension (Factor I) and Abstract Reasoning (Factor V) are more highly correlated than any other pair of factors $(r=0.39)$. Since these two dimensions are both hypothetically linked to left hemisphere functioning, a combined score (viz., Verbal-abstract functioning) was computed by averaging Factors I and V. Thus, six scores, one for each factor and a combined one for Verbal-abstract functioning, were used in subsequent analyses.

\section{Lateralization Analyses}

In order to index each area of cognitive or sensorimotor functioning against overall level of performance, each set of factor scores was regressed on three or more of the other dimensions. More specifically, Factor I (Verbal Comprehension) scores were regressed on Factors II, III, and IV (Factor V, 
TABLE 1

Means and Standard Deviations $(N=108)$

\begin{tabular}{|c|c|c|}
\hline Variable & Mean & $S D$ \\
\hline Information ${ }^{\mathbf{a}}$ & 8.03 & 2.68 \\
\hline Comprehension & 9.42 & 3.41 \\
\hline Arithmetic & 8.45 & 2.61 \\
\hline Similarities & 9.54 & 2.81 \\
\hline Vocabulary & 8.58 & 2.93 \\
\hline Digit Span & 8.81 & 2.88 \\
\hline Picture completion & 8.78 & 2.22 \\
\hline Picture arrangement & 8.24 & 2.63 \\
\hline Block design & 8.42 & 2.59 \\
\hline Object assembly & 7.39 & 2.69 \\
\hline Digit symbol & 8.15 & 2.85 \\
\hline Category- $\mathrm{I}^{\mathrm{b}}$ & .10 & .36 \\
\hline Category-II & .64 & .65 \\
\hline Category-III & 18.55 & 11.37 \\
\hline Category-IV & 15.43 & 11.75 \\
\hline Category-V & 14.45 & 6.91 \\
\hline Category-VI & 9.23 & 6.52 \\
\hline Category-VII & 5.28 & 2.49 \\
\hline TPT-Dominantc & 8.02 & 2.42 \\
\hline TPT-Nondominant & 7.44 & 2.53 \\
\hline TPT-Both hands & 5.08 & 2.83 \\
\hline TPT-Blocks (dominant) & 8.10 & 2.76 \\
\hline TPT-Blocks (nondominant) & 8.56 & 2.55 \\
\hline TPT-Blocks (both hands) & 9.38 & 1.83 \\
\hline TPT-Memory & 6.43 & 1.75 \\
\hline TPT-Localization & 3.08 & 2.34 \\
\hline Speech Perception ${ }^{b}$ & 10.14 & 6.60 \\
\hline Seashore Rhythma & 7.49 & 3.54 \\
\hline Tonal Memory ${ }^{d}$ & 15.87 & 6.90 \\
\hline Raven's Progressive Matrices & 36.33 & 10.92 \\
\hline Finger Tapping-Dominante & 42.09 & 7.70 \\
\hline Finger Tapping-Nondominant & 37.94 & 6.37 \\
\hline Reading Recognition & 8.95 & 3.33 \\
\hline Reading Comprehension & 8.22 & 3.05 \\
\hline Spelling & 7.85 & 2.69 \\
\hline Arithmetic & 6.58 & 2.27 \\
\hline Trail Making-A $A^{n}$ & 38.04 & 14.59 \\
\hline Trail Making-B & 102.05 & 52.80 \\
\hline Serial Seven's & 100.86 & 65.91 \\
\hline Grip Strength-Dominants & 33.83 & 12.94 \\
\hline Grip Strength-Nondominant & 31.42 & 12.59 \\
\hline Tactile Finger Localization-Right ${ }^{b}$ & 1.95 & 2.46 \\
\hline Tactile Finger Localization-Left & 1.92 & 2.24 \\
\hline Tactile Form Recognition-Right ${ }^{\mathrm{H}}$ & 13.38 & 9.27 \\
\hline Tactile Form Recognition-Left & 11.31 & 4.59 \\
\hline
\end{tabular}

Note. The variables are expressed in the following units: ascaled scores; berrors; ${ }^{c}$ minutes; ${ }^{\mathrm{d}}$ correct; ${ }^{\mathrm{e}}$ number per 10 seconds; 'grade level; skilograms; 'hseconds. 
TABLE 2

Characteristics of Correlation Matrix

\begin{tabular}{lc}
\hline Index & Value \\
\hline Kaiser-Meyer-Olkin estimate of variables' sampling adequacy & .83 \\
Bartlett's test of sphericity & $x^{2}=3,276.03^{*}$ \\
& $(990 \mathrm{df})$ \\
No. of off-diagonal elements $>.09$ in anti-image covariance matrix & 44 \\
& $(2.22 \%)$ \\
\hline
\end{tabular}

Note. $N=108$. All indices are within acceptable limits. ${ }^{*} \mathrm{p}<.001$.

Abstract Reasoning, was excluded because of its close association with Factor I); combined Factors I and V (Verbal Comprehension and Abstract Reasoning) scores on Factors II, III, and IV. From these regressions, residual scores for Verbal Comprehension, Motor Skills, Perceptual Organization, Selective Attention, and Abstract Reasoning, and combined Verbal Comprehension and Abstract Reasoning (i.e., scores remaining after performance on the other factors was controlled) were determined. These residual scores served as dependent variables in subsequent analyses.

Six analyses of variance, one for each of the six sets of residual scores, were conducted across the four laterality categories. A priori contrasts were then made on the basis of the hypotheses: (a) Subjects with left-sided foci had been predicted to achieve the lowest residual scores on Verbal Comprehension, Abstract Reasoning, and the combined index; (b) those with rightsided foci to achieve lowest residual scores on Perceptual Organization; (c) those with generalized electrographic abnormalities to achieve highest residual scores on Verbal Comprehension, Perceptual Organization, Abstract Reasoning, and the combined index. (Note that generalized seizures, whatever the absolute magnitude of their effects might be, in all likelihood, would equally impair both right- and left-sided functions.) No predictions were made about performance on Motor Skills (Factor II) or Selective Attention (Factor IV).

Means, standard deviations, and test statistics are shown in Table 4. It should be noted that no significant differences were found for Factors II $(F=1.014$; n.s. $)$ and IV $(F=1.960$; n.s. $)$. For all analyses, the variances of the four groups were homogeneous.

A clear structure is easily seen in this set of variables, even though several of them have a complexity (as indicated by their loading on more than one factor) that will require further explanation and investigation. The subtests of the Wechsler Adult Intelligence Scale comprise a set of useful "marker" variables that serve to identify these dimensions. In many respects, the patterns which have emerged for these epileptic patients are comparable to 
TABLE 3

Oblique Factor Pattern Matrix

\begin{tabular}{|c|c|c|c|c|c|c|}
\hline & \multicolumn{6}{|c|}{ Factor } \\
\hline & 1 & 2 & 3 & 4 & 5 & $\mathrm{~h}^{2}$; \\
\hline \multicolumn{7}{|l|}{ Variable: } \\
\hline Information & 82 & & & & & 73 \\
\hline Comprehension & 73 & & -40 & & & 68 \\
\hline Arithmetic & 34 & & & -33 & & 44 \\
\hline Similarities & 68 & & & & & 56 \\
\hline Vocabulary & 97 & & & & & 88 \\
\hline Digit Span & & & & -52 & & 47 \\
\hline Picture Completion & 46 & & -33 & & & 53 \\
\hline Picture Arrangement & 32 & & -32 & & & 39 \\
\hline Block Design & & & -42 & & & 47 \\
\hline Object Assembly & & & -51 & & & 50 \\
\hline Digit Symbol & & & & -43 & & 42 \\
\hline Category-I & & & & & & 06 \\
\hline Category-II & & & & & & 09 \\
\hline Category-III & & & & 38 & & 27 \\
\hline Category-IV & & & & & 41 & 39 \\
\hline Category-V & & & & & 73 & 53 \\
\hline Category-VI & & & & & 85 & 67 \\
\hline Category-VII & & & & & 75 & 64 \\
\hline TPT-Dominant & & & 57 & & & 48 \\
\hline TPT-Nondominant & & & 65 & & & 59 \\
\hline TPT-Both hands & & & 69 & & & 65 \\
\hline TPT-Blocks (dominant) & & & -67 & & & 57 \\
\hline TPT-Blocks (nondominant) & & & -61 & & & 51 \\
\hline TPT-Blocks (both hands) & & & -51 & -31 & & 39 \\
\hline TPT-Memory & & & -50 & & & 44 \\
\hline TPT-Localization & & & -56 & & & 53 \\
\hline Speech Perception & -33 & & & & & 30 \\
\hline Seashore Rhythm & & & & 36 & & 26 \\
\hline Tonal Memory & & & & & & 28 \\
\hline Raven's Progressive Matrices & 38 & & & -37 & & 63 \\
\hline Finger Tapping-Dominant & & 45 & & -41 & & 43 \\
\hline Finger Tapping-Nondominant & & 33 & & -41 & & 32 \\
\hline Reading Recognition & 82 & & & -31 & & 85 \\
\hline Reading Comprehension & 72 & & & & & 66 \\
\hline Spelling & 75 & & & -45 & & 37 \\
\hline Arithmetic & 38 & & & -36 & & 53 \\
\hline Trail Making-A & & & & 68 & & 50 \\
\hline Trail Making-B & & & & 67 & & 58 \\
\hline Serial Seven's & & & & 51 & & 36 \\
\hline Grip Strength-Dominant & & 95 & & & & 87 \\
\hline Grip Strength-Nondominant & & 93 & & & & 85 \\
\hline Tactile Finger Localization-Right & & & & 44 & & 28 \\
\hline Tactile Finger Localization-Left & & & & 41 & & 33 \\
\hline Tactile Form Recognition-Right & & & & 38 & & 17 \\
\hline Tactile Form Recognition-Left & & & 31 & 39 & & 32 \\
\hline
\end{tabular}

(continued) 
TABLE 3

Continued

\begin{tabular}{lrrrrr}
\hline & \multicolumn{5}{c}{ Factor Pattern Correlations } \\
\cline { 2 - 5 } & \multicolumn{1}{c}{1} & 2 & 3 & 4 & 5 \\
\hline 1. & 100 & 17 & -24 & -31 & -39 \\
2. & & 100 & -10 & -14 & -12 \\
3. & & & 100 & 32 & 31 \\
4. & & & & 100 & 29 \\
5. & & & & 100 \\
\hline
\end{tabular}

Note. $N=108$. Decimais for the loadings, communalities $\left(\mathrm{h}^{2}\right)$, and factor pattern correlations have been omitted. Loadings with an absolute value less than .30 have been deleted.

TABLE 4

Predicted Pattern and Actual Fator Seore Means as a Function of Laterality Index and a priori Contrast $t$-ratios

\begin{tabular}{|c|c|c|c|c|c|}
\hline \multirow[b]{2}{*}{ Halstead Factors } & \multicolumn{4}{|c|}{ Lateralization Index } & \multirow[b]{2}{*}{ I-ratio } \\
\hline & $\begin{array}{c}\text { Right } \\
(N=29)\end{array}$ & $\begin{array}{c}\text { L.eft } \\
(N=13) .\end{array}$ & $\begin{array}{l}\text { Bilateral } \\
(N=10)\end{array}$ & $\begin{array}{l}\text { Generalized } \\
(N=35)\end{array}$ & \\
\hline $\begin{array}{l}\text { Verbal comprehensio } \\
\text { Predicted pattern } \\
\text { Means }\end{array}$ & -.13 & $\begin{array}{l}\text { low } \\
-.38\end{array}$ & -.14 & $\begin{array}{l}\text { high } \\
+19\end{array}$ & $1.74 *$ \\
\hline $\begin{array}{l}\text { Simple motor skills } \\
\text { Predicted pattern } \\
\text { Means }\end{array}$ & +.22 &.- .00 & +.33 & -.04 & $\begin{array}{l}\text { no prediction } \\
\text { none }\end{array}$ \\
\hline $\begin{array}{l}\text { Perceptual organizati } \\
\text { Predicted pattern } \\
\text { Means }\end{array}$ & $\begin{array}{l}\text { Low } \\
-.33\end{array}$ & -.21 & -.07 & $\begin{array}{l}\text { high } \\
+.31\end{array}$ & $2,66 * *$ \\
\hline $\begin{array}{l}\text { Selective attention } \\
\text { Predicted pattern } \\
\text { Means }\end{array}$ & -.17 & +.25 & +.21 & +.01 & $\begin{array}{l}\text { no prediction } \\
\text { none }\end{array}$ \\
\hline $\begin{array}{l}\text { Abstract reasoning } \\
\text { Predicted pattern } \\
\text { Means }\end{array}$ & -.07 & $\begin{array}{l}\text { low } \\
-.43\end{array}$ & -.21 & $\begin{array}{l}\text { high } \\
+.29\end{array}$ & $2.45^{* *}$ \\
\hline
\end{tabular}

Note. Overall means do not sum to zero because only 87 of the origina 108 subjects were included.

$* p<.05$ (one-tailed test). ** $p<.01$ (one-tailed test). 
what has been observed in other neurologically impaired populations as well as for normal adults. Moreover, the distinction made by Lezak (1983) that broadly groups sets of neuropsychological variables into categories of verbal, nonverbal, and mental activity functions is readily applicable here. The Verbal Comprehension, Abstract Reasoning, Selective Attention, Perceptual Organization, and Motor Skills factors may be all usefully subsumed within one of these broad categories.

Although the simplicity of this scheme is readily visible in our results, it is important to recognize that no absolute fit of the five-factor model obtained: The quality of the pattern of performance remains more complex than the model (as Newby et al., (1983) also found). This undoubtedly implicates the impact of these patients' seizures and their medications upon higher-order abilities, even though the effects of localized EEG abnormalities are consistent with our present state of knowledge regarding cerebral specialization (Luria, 1980). In our results, it is not clear, though, to what extent a somewhat greater preponderance of men $(55 \%)$ has "clarified" the usefulness of these EEG indices. Kupke and Lewis (1985) found, for example, that lateralization of function on the WAIS was clearer for men than women. However, Wieser, Hailemariam, Regard, and Landis (1985) did report recently, in a study of four patients with unilateral epileptic discharges whom they monitored with depth EEG recordings, that ". . . impairment in cognitive function correlated with focal electric activity... [that] is task and hemisphere specific, i.e., inhibits only cognitive functions dominantly processed by the discharging hemisphere . . ." (p. 25).

The results for performance on the Selective Attention dimension reaffirms that these processes must be partly based, and dependent, upon the general integrity of multiple systems of higher cortical function. Evidence which emerges from a consideration of the impact of generalized versus local-onset of seizure activity on neurocognitive abilities (e.g., Giordani et al., 1985) suggests disruptions in this highly complex system may be initiated by virtually any disturbance of higher cortical function (Neisser, 1976).

Our results are most consistent, then, with that stream of previously published research (e.g., Meyer \& Yates 1969; Newby et al., 1983; Royce et al., 1976) which indicates that, with careful attention to methodological issues, structural models of mental or cognitive space may be developed for neurologically impaired patients in a manner that does not sharply diverge from those previously developed for normal populations. Moreover, the relationships of such structural variables, as we have developed in this investigation, to personality traits, behavior (e.g., family functioning), and the temporal patterning of seizure disorders remain to be specified.

In this particular population, one must also recognize that, even though the neuropathology that underlies the development (and, often, progression) of seizure activity may be stable, such pathology may produce second- 
ary effects in any number of systems (Goddard, 1983). Further controlled investigation along these avenues, as previously adumbrated by Hermann \& Whitman (1984), is currently proceeding in our laboratory with epileptic patients and their families.

Acknowledgement - The authors would like to gratefully acknowledge the personnel and patients of the Comprehensive Epilepsy Program (F. E. Dreifuss, M.D., Director, University of Virginia Medical Center) for their invaluable assistance. We would also like to specifically acknowledge the efforts of Bruno Giordani, Ph.D., for his work in assembling and maintaining the initial data archive which contributed to this study. Acknowledgement is also due F. E. Dreifuss, M.D., J. C. Sackellares, M.D., E. Faught, M.D., and J. Margraf, M.D. for their diligence in reviewing the EEG data.

\section{REFERENCES}

Boll, T. (1978). Diagnosing brain impairment. In B. Wolman (Ed.), Clinical diagnosis of mental disorders pp. 601-675. New York: Plenum.

Brown, S. W., \& Reynolds, E. H. (1981). Cognitive impairment in epileptic patients. In E. Reynolds \& M. Trimble (Eds.), Epilepsy and psychiatry pp. 147-164.

Camfield, P. R., Gates, R., Ronen, G., Camfield, C., Ferguson, A., \& MacDonald, G. W. (1984). Comparison of cognitive ability, personality profile, and school success in epileptic children with pure right versus left temporal lobe EEG foci. Annals of Neurology, 15, 122-126.

Carroll, J. B., \& Maxwell, S. E. (1979). Individual differences in cognitive abilities. In M. Rosenzweig \& L. Porter (Eds.), Annual review of psychology, 30, 618-640. Palo Alto, CA: Annual Reviews, Inc.

Cattell, R. (1966). A scree test for the number of factors. Multivariate Behavioral Research, 1, 245.

Dodrill, C. (1981). The neuropsychology of epilepsy. In S. Filskov \& T. Boll (Eds.), Handbook of clinical neuropsychology. New York: Wiley-Interscience.

Dodrill, C. (1986). Correlates of generalized tonic-clonic seizures with intellectual, neuropsychological, emotional, and social function in patients with epilepsy. Epilepsia, 27, 399-411.

Dodrill, C. B., \& Wilkus, R. J. (1978). Neuropsychological correlates of the electroencephalogram in cpileptics: III. Generalized non-cpilcptiform abnormalitics. Epilepsia, 19, 453-462.

Dzuiban, C., \& Shirkey, E. (1974). When is a correlation matrix suitable for factor analysis? Psychological Bulletin, 81, 358-361.

Epilepsy Foundation of America (1975). Basic statistics on the epilepsies. Philadelphia: Davis.

Fowler, P., Richards, H., \& Boll, T. (1980). WAIS factor patterns of epileptic and normal adults. Journal of Clinical Neuropsychology, 2, 115-123.

Giordani, B., Berent, S., Sackellares, J. C., Rourke, D., Seidenberg, M., O'Leary, D. S., Dreifuss, F. E., \& Boll, T. J. (1985). Intelligence test performance of patients with partial and generalized seizures. Epilepsia, 27, 399-411.

Goddard, G. V. (1983). The kindling model of epilepsy. Trends in Neurosciences, 275-279.

Halstead, W. C. (1947). Brain and intelligence: A quantitative study of the frontal lobes. Chicago: University of Chicago Press.

Hermann, B. P., \& Whitman, S. (1984). Behavioral and personality correlates of epilepsy: A review, methodological critique, and conceptual model. Psychological Bulletin, 95, 451-497.

Kupke, T., \& Lewis, R. (1985). WAIS and neuropsychological tests: Common and unique variance within an epileptic population. Journal of Clinical and Experimental Neuropsychology, 7, 353-366. 
Ladavas, E., Umilta, C., \& Provinciali, L. (1979). Hemisphere-dependent cognitive performances in epileptic patients. Epilepsia, 20, 493-502.

Lezak, M. D. (1983). Neuropsychological assessment (2nd ed.). New York: Oxford University Press.

Loiseau, P., Strube, E., Broustet, D., Battellochi, S., Gomeni, C., \& Morselli, P. L. (1983). Learning impairment in epileptic patients. Epilepsia, 24, 183-192.

Luria, A. R. (1980). Higher cortical functions in man. (B. Haigh, Trans.) New York: Basic Books.

Meyer, V., \& Yates, A. (1955). Intellectual changes following temporal lobectomy for psychomotor epilepsy: A preliminary communication. Journal of Neurology, Neurosurgery, \& Psychiatry, 18, 44-52.

Neisser, U. (1976). Cognition and reality. San Francisco: W. H. Freeman and Company.

Newby, R., Hallenbeck, C. E., \& Embretson, S. (1983). Confirmatory factor analysis of four general neuropsychological models with a modified Halstead-Reitan Battery. Journal of Clinical Neuropsychology, 5, 115-133.

Nie, N., Hull, C., Jenkins, J., Steinbrenner, K., \& Bent, D. (1979). Statistical package for the social sciences. Ncw York: McGraw-Hill.

Pincus, J. H., \& Tucker, G. J. (1985). Behavioral neurology (3rd ed.). New York: Oxford University Press.

Reitan, R. M. (1966). A research program on the psychological effects of brain lesions in human beings. In N. R. Ellis (Ed.), International review of research in mental retardation (Vol. 1). New York: Academic Press.

Reitan, R. M., \& Davidson, L. A. (Eds.). (1974). Clinical neuropsychology: Current status and applications. Washington, DC: Winston.

Reynolds, E. M., \& Trimble, M. R. (Eds.). (1981). Epilepsy and psychiatry. New York: Churchill Livingstone.

Royce, J. R., Yeudall, L. T., \& Bock, C. (1976). Factor analytic studies of human brain damage: I. First and second-order factors and their brain correlates. Multivariate Behavioral Research, 381-418.

Russell, E. W., Neuringer, C., \& Goldstein, G. (1970). Assessment of brain damage: A neuropsychological key approach. New York: Wiley-Interscience.

Stores, G. (1981). Problems of learning and behaviour in children with epilepsy. In E. Reynolds \& M. Trimble (Eds.), Epilepsy and psychiatry, 33-48.

Swiercinsky, D. (1978). Manual for the adult neuropsychological evaluation. Springfield, IL: Charles $C$. Thomas.

Swiercinsky, D. (1979). Factorial pattern description and comparison of functional abilities in neuropsychological assessment. Perceptual and Motor Skills, 48, 231-241.

Wieser, G., Hailemariam, S., Regard, M., \& Landis, T. (1985). Unilateral limbic epileptic status activity: Stereo EEG, behavioral, and cognitive data. Epilepsia, 26, 19-29. 